\title{
Analysis and Research on the Problem of Rural Left behind Elderly
}

\author{
Ting Shan \\ Department of Law and Political Science, North China Electric Power University, Baoding, China, \\ 071000
}

1141440430@qq.com

Keywords: Rural left behind elderly; Unbalanced development of urban and rural areas; The situation of material life; Spiritual life

\begin{abstract}
With a large number of rural labor into the city, Chinese urbanization process is accelerating, which also led to a series of social problems. As most of the rural laborers into the city, rural areas have left only three main bodies of women, children and the elderly, which is called the image of the 386199 forces. Because there are more opportunities and good education conditions in the city, migrants try their best to bring their spouses or children to the city to work together or provide better learning and living environment, and the old man has become the rural "backbone". And because of various factors, this group is still expanding, and pension issues have gradually become a problem that cannot be ignored. Based on the above background, this paper will analyze and study the problems of the left behind elderly in rural areas, in order to provide a reference for the current social problems.
\end{abstract}

\section{Introduction}

Due to uneven development of urban and rural areas, the city has a large number of resources and development opportunities, attracting a large number of rural youth to enter the city to seek better development. It is because of their influx, providing the city with a sufficient labor force, but the opposite is the shortage of rural labor. At this time the children, women and the elderly were left in the rural areas. migrants try their best to bring their spouses or children to the city to work together or provide better learning and living environment, and the old man has become the rural "backbone". In addition, due to various reasons, the number of left behind old people is gradually expanding, and it is not conducive to improving the overall level of life of the people and the overall development of china. Under this background, this paper attempts to alleviate the current social problems in the rural elderly.

\section{Current Situation of the Rural Left behind Elderly in China}

Through the collection of information and in-depth study, we will carry out a comprehensive analysis of the living situation of the rural left behind elderly in two aspects.

Material Living Conditions of Rural Left behind Elderly. Because Chinese urban and rural economic development is Unbalanced, city income and living standard are significantly higher than that in most rural areas. Income and quality of life in rural areas have limited the life and development of the rural families, so most of the young people in order to improve the situation of family life, have to choose to enter the city to work. Through the investigation and analysis, we can find that the main income of the elderly is their own or their spouse's labor income, followed by the children out of funding. In view of this, children have to go out to work to improve the lives of the elderly seem to have a certain role. This paper continues to study the main expenditure for the elderly, we found the old man the main overhead is food and clothing and medical costs. These are the necessary expenses, and there is almost no entertainment spending. That is to say, the rural elderly enjoy consumption is almost zero, and life is still tight, poverty is also very common. From the aspects of the whole, although children go out to work to earn money, but the improvement of the rural life of the elderly is not much affected, and the money they earn is mainly spent on their grandchildren, so in general, this is not the impact on the elderly. 
The Spiritual Life of the Left behind Elderly in Rural Areas. Most people can understand the children are not around, but still very eager to live together with the kids. Most old people's life is very lonely. Their spiritual life is very scarce, and have children and grandchildren as spirit. And because of the ability to learn new things become weak, the old man is also difficult to find suitable way for their own entertainment. The old people's mental condition is extremely depressed, which reflects the lack of spiritual care for the elderly in rural areas and the miss to migrant workers in the city.

Through the above study, migrant children do not significantly improve the lives of the elderly, and the elderly are still suffering from the pressure of life. With the increase of age, there are more and more problems in the physical appearance of the left behind elderly and expenses on medical care has also increased. Elderly people themselves are difficult to obtain a larger income, which makes the life pressure of the elderly in rural areas continue to increase. All of this are not conducive to the elderly have a good mental state.

Because of the vast majority of the rural elderly life is very poor and the children also do the hard work in the city earning a minimum wage and having low social status. Coupled with the increase of age, the same old generation of friends and relatives have also died. This will make the elderly feel depressed and weary, and lead to elderly have a unhealthy mental state,

\section{The Reason of Producing a Large Number of Rural Left behind Elderly in China}

Uneven Development of Urban and Rural Areas and Dual Household Registration System. China began to appear a large number of rural elderly in 1980s, and this is inseparable from Chinese urban industrialization at the same time. Due to the rapid development of the city, it also requires a lot of labor to support the city. The rapid development of urban economy, employment opportunities, education and other rich resources have attracted a large number of migrant workers to stay in the city. And the more people stay in the city, the more prosperous the city's development, which further attract more rural labor to make a living in the city. So the cycle, the gap between urban and rural areas has gradually increased, which has once again prompted more people into the city, making the rural elderly more and more left.

Since young people are choosing to live in the city, why not bring their own parents? In fact, this is compelling. The difference between urban and rural accounts led to the difficulty of rural young people in the city to buy a house and it is difficult to enjoy the social welfare of the city. The majority of the elderly said their children cannot settle in the city is one of the important reasons they left behind in rural areas.

The Influence of Traditional Thought on Rural Left behind Elderly. Our country is a traditional agricultural country, and the land is the foundation to rely on, echoing with the traditional culture of our country. Most people are not willing to leave for home, and do not want to leave their roots. What's more, our country has always attached great importance to the land, increasing the sense of security of the elderly, and many elderly people prefer to endure loneliness rather than entering a strange environment. These factors make the number of elderly people left in rural areas.

Chinese Traditional Culture and Moral Decline. Since ancient times, we have tradition of respect the old and cherish the young. However, with the gradual decline of the traditional culture, contemporary young people understand the "filial piety" is too one-sided, they believe that providing sufficient material support is the filial piety and gratitude to their parents and this is also a major cause of rural left behind elderly.

The Development of Medical Technology in Our Country. According to the WHO report, the average life expectancy in China is 72 years old and the average male life expectancy was 70 years, the average life expectancy of women was 74 years. Compared with the early years of the Republic, the average life expectancy has been prolonged for more than 20 years. and this number will continue to increase. It is because of Chinese economic development and the progress of medical technology extend the majority of our population life. Of course, this also caused the increase of the elderly in China. 


\section{Countermeasures to Alleviate the Phenomenon of Left behind Old People in Rural Areas of China}

Narrowing the Development Gap between Urban and Rural Areas in China. Because of the unbalanced development of urban and rural areas, a large number of rural labor force quickly ran to the cities, and makes a large number of elderly people have been left in the rural areas. In this regard, the state should strengthen the construction of rural areas. First of all, all levels of aging organizations, civil affairs, health, labor and other departments should play their respective roles, improve the rural security system, and ease the pressure of life of the elderly. Secondly, to accelerate the transformation of the rural economy, make a scientific plan, attracting labor return loss. Finally, strengthen rural infrastructure and increase public construction. Do our best to narrow the gap between urban and rural development, so that young people are willing to return to their home and build their hometown.

Perfect the Household Registration System. Due to the restrictions of the household registration system, many migrant workers cannot be settled in the city, which also led to the migrant workers in the city cannot have a stable life, and cannot bring their parents came to the city together. Therefore, we should make some changes to the household registration system, such as allowing migrant workers living in the city for a period of time to buy a house in the city and enjoy the city's social welfare. Only let the migrant workers in urban areas have a stable life, it is possible to let their parents no longer stay in rural areas, missing their children day and night.

Strengthening the Construction of Pension Services. With the development of our country, the traditional mode of care for the elderly is also known as the family pension model, its function is gradually weakening. We should strengthen the construction of rural pension services so that the rural pension gradually socialized. When the child's economic burden is reduced, naturally by some young people are willing to return home, to accompany the parents around, which helps to solve the problem of rural left behind elderly. When the child's economic burden is reduced, there will be some young people are willing to return home, and to accompany their parents around, which helps to solve the problem of rural left behind elderly.

Strengthening the Construction of the Traditional "Filial Piety" Culture in China. Affected by the current market economy, most young people attach great importance to material and despise the spirit and moral cultivation. They think that as long as they meet the material needs of their parents, they have done the filial piety, while ignoring the spiritual needs of parents. Therefore, we should strengthen the construction of China's traditional culture of "filial piety", and further promote the Chinese traditional virtues of respecting, establishing a good social habits of love and respect for elders, and encouraging their children to go home often, giving their parents more spiritual comfort.

\section{Conclusion}

The elderly left behind in rural is a long neglected group. When really pay attention to them, the group has grown to a level that must be paid attention to. in 2013 , the number of elderly population exceeded 200 million mark, aging level reached $14.8 \%$. The problem of rural elderly is not only a social problem, if mishandled; it is likely to cause intense social contradictions which can affect the city and rural economic development and the sustainable economic development of our country. So we must pay attention to the group of rural left behind elderly, understand their current living situation and mental state and know what they need. At the same time, only through the national coordination of all aspects, and carry out macroeconomic regulation and control from various aspects can we really solve the problem of rural left behind elderly. 


\section{References}

[1] Xiao Jiehong. The Spiritual Life of the Left Behind Elderly in Rural Areas and Its Countermeasures [J].Journal of Chifeng University(Philosophy and Social Science Chinese Edition) , 2012,10:105-107. (In Chinese)

[2] Lu Haiyang, Qian Wenrong. Study on the Effect of Children's Migrant Workers on the Life of Left behind Elderly in Rural Areas [J]. Issues in Agricultural Economy, 2014, 06:24-32+110. (In Chinese)

[3] Yin Pingjun, Huang Wenlin. Research Status and Trends of Rural Left behind Elderly [J]. Jiangxi Social Sciences, 2011, 02:195-199. (In Chinese)

[4] Zhou Zhuping. Research on the Income of the Left behind Elderly in Rural Areas [J].Population Journal, 2009, 05:32-37.

[5] Kong Fansen. Study on the Impact of Rural Left behind Elderly Model on Quality of Life in Henan Province [J]. Modern Business Trade Industry, 2016, 04:158-159.

[6] Liu Yan. Ethical Problems and Countermeasures of Rural Left behind Elderly [J]. Contemporary Education Research and Teaching Practice, 2016, 09:252-253.

[7] Liu Mei, Xu Jie, Wang Jinlong, Ge Suyuan, Tang Cheng, high total. Study on the Influencing Factors of Mental Health Status of Left Behind Elderly People in Rural Areas [J]. Medicine \& Philosophy (A), 2015, 10:46-49.

[8] Zhao Xiaoli. Study on the Countermeasures of Spiritual Support for the Elderly in Chinese Rural Areas [J]. Business Economy, 2015, 10:19-20+32.

[9] Shan Guoyan. Analysis of the Old Age Security Problem of the Left behind in China [J]. Academics, 2015, 10:227-235.

[10]Tang Hao, Shi Guangrong. Life Satisfaction and Its Influencing Factors of Rural Left behind Elderly [J]. Journal of Anhui Agricultural University (Social Sciences Edition), 2015, 05:80-86. 